Introduction: Hypopharyngeal cancer accounts for $3-5 \%$ of all squamous-cell carcinoma (SCC) of the head and neck and has one of the worst prognoses. The aim of the study was to evaluate oncologic and functional treatment outcomes in patients with T3-T4a squamous cell hypopharyngeal and laryngeal cancer.

Material and methods: Retrospective analysis of the material from one treatment site included 90 patients ( 81 male, 9 female) who had undergone surgery between 1986 and 2010. Their mean age was 55.06 years (range 36-75).

Results: TNM (T - tumour, N - node, $M$-metastasis) staging assessment was feasible in 70 treatment-naïve patients (77.78\%): 57 (63.33\%) were classified to stage T4a, and 13 were classified to T3 (14.44\%). Cervical lymphadenopathy was observed in $53(63.3 \%)$ patients; in 44 patients (48.89\%) postoperative histopathology confirmed metastatic disease. G2 or G3 SCC was detected in $80 \%$ of patients. All patients underwent laryngopharyngoesophagectomy (LPE). Digestive tract reconstruction was performed using one of two methods: jejunal autograft (JA) in 79 patients (87.78\%) -Group A or ileocolic autograft (IA) in 11 patients (12.22\%) - Group B Comparative statistical analysis of both groups showed statistically significant differences only for substitute speech production. The mean survival time of patients from both groups was 2.21 years after reconstruction surgery. Conclusions: JA or IA for digestive tract reconstruction in patients after LPE are burdened with high risk of complications but offer patients the chance of a normal oral diet shortly after surgery. Ileocolic autograft enables rapid production of substitute speech.

Key words: hypopharynx cancer, digestive tract reconstruction, jejunal autograft, ileocolic autograft.

Contemp Oncol (Pozn) 2021; 25 (1): 28-32 DOI:https://doi.org/10.5114/wo.2021.105074

\section{Jejunal and ileocolic free flaps for digestive tract reconstruction following pharyngo-laryngo- oesophagectomy - 30 years of single-centre experience}

\author{
Ewa Osuch-Wójcikiewicz ${ }^{1}$, Daniel Majszyk ${ }^{1}$, Antoni Bruzgielewicz ${ }^{1}$, \\ Tadeusz Grochowiecki ${ }^{2}$, Sławomir Nazarewski' ${ }^{2}$, Piotr Chęciński ${ }^{1}$, \\ Kazimierz Niemczyk ${ }^{1}$
}

\author{
${ }^{1}$ Department of Otorhinolaryngology Head and Neck Surgery, Medical University \\ in Warsaw, Warsaw, Poland \\ 2Department of General, Vascular and Transplant Surgery, Medical University \\ in Warsaw, Warsaw, Poland
}

\section{Introduction}

Hypopharyngeal cancer accounts for $3-5 \%$ of all squamous cell cancers of head and neck, and has one of the worst prognoses among malignancies located in this region [1, 2]. Oligosymptomatic onset of the disease, its rapid spread, and early metastasis in regional lymph nodes make the treatment of advanced hypopharyngeal cancers difficult and burdened with high risk of failure. Typically, the disease affects men, long-time smokers, who are often alcohol abusers, suffering from systemic conditions associated with this kind of lifestyle. Advanced stage of the disease (T3-T4) is diagnosed in $70 \%$ to $85 \%$ of patients, when radical treatment options are very limited and overall survival rates range between $15 \%$ and $45 \%$ [1-5]. The presence of enlarged lymph nodes in the neck is most commonly the first visible sign of the disease. In 20-25\% of patients, distant metastases have been detected at various sites - in the lungs, liver, or bones [6, 7]. A vast majority of hypopharyngeal and laryngeal cancers are squamous cell carcinomas. Diagnostic imaging techniques (CT, MRI, PET) are used to determine the advance of the disease. The patients with advanced hypopharyngeal cancer undergo surgical treatment (laryngopharyngoesophagectomy - LPE) followed by radiotherapy and radiochemotherapy. Jejunal autograft (JA) or ileocolic autograft (IA) with vascular microanastomosis are used for the reconstruction of the digestive tract.

The aim of this study was to evaluate oncologic and functional treatment outcomes in patients with T3-T4 hypopharyngeal and laryngeal cancer who underwent LPE with digestive tract reconstruction using JA and IA.

\section{Material and methods}

The analysis included 90 patients operated for T3-T4a hypopharyngeal and laryngeal cancer between 1986 and 2010. This group comprised $81(90 \%)$ males and 9 (10\%) females. The patients' mean age was 55.06 years (36-75).

Two groups of patients were identified based on the intestinal fragment used for reconstruction:

- Group A - patients with A,

- Group B - patients with A.

Clinical characteristics, complications, and treatment outcomes were compared and analysed. 
Swallowing function was assessed in both groups: before surgery and 3 months after surgery, X-ray of the oesophagus was performed using diluted barium sulphate, and swallow test was conducted with $250 \mathrm{ml}$ of liquid. A 3-level scale proposed by Nazarewski was used for the evaluation of swallowing efficiency [8]. Three months after reconstruction surgery, voice and substitute speech were assessed on a 4-point scale (ranging from very good to poor).

\section{Statistical analysis}

A comprehensive statistical analysis was performed. The methods adequate for the types of variables were selected for the analysis. A significance level $\alpha=0.05$ was adopted for statistical hypothesis testing.

For each variable, depending on its type, basic statistical values were calculated. The normality of continuous variable distribution was verified using the Lilliefors test based on the Kolmogorov-Smirnov test and the Shapiro-Wilk's W test. Due to the small number of subjects in the analysed groups, the Mann-Whitney $U$ test was used for analyses.

The correlations between discrete variables were evaluated with exact Pearson's $\chi^{2}$ test, $\chi^{2}$ maximum likelihood test, Yates' $\chi^{2}$ test, and exact Fisher's test.

Survival curves were estimated using Kaplan-Meier analysis. Survival curves were compared based on Wilcoxon's test of Gehan, Cox-Mantel, and Cox F tests.

The statistical analysis was conducted using StatSoft Inc. (2014) Statistica ver. 12.

\section{Results}

The largest group consisted of city inhabitants (90\% patients), smokers (96.66\% patients), and high-volume spirit abusers (57.78\%). TNM (T - tumour, N - node, M metastasis) staging assessment was feasible in 70 treatment-naïve patients (77.78\%): 57 (63.33\%) patients had T4a disease, and 13 patients were classified to T3 (14.44\%).

In 53 patients (63.3\%), CT scan showed cervical lymphadenopathy. In 44 patients (48.89\%), postoperative histopathology examination confirmed metastasis in the resected lymph nodes, while in the remaining patients, the lymph nodes showed reactive changes

All patients with cervical lymphadenopathy 57 (63.3\%) underwent unilateral neck dissection; 8 (8.89\%) of them also underwent contralateral selective neck dissection

Table 1. Quantitative comparison of intraoperative complications in both groups

$\begin{array}{lcc}\text { Intraoperative complications } & \text { Group A } & \text { Group B } \\ \text { Venous thrombosis } & 1(1.1 \%) & 1(11.1 \%) \\ \text { Arterial thrombosis } & 12(14 \%) & 1(11.1 \%) \\ \text { Changing a vessel } & 4(4.9 \%) & 1(11.1 \%) \\ \text { Harvesting second autograft } & 2(2.4 \%) & - \\ \text { Restoring patency to a vessel } & 5(6.2 \%) & 1(11.1 \%) \\ \text { Failure } & 2(2.4 \%) & -\end{array}$

(levels I-III) because of lymphadenopathy on both sides of the neck.

Histopathology findings:

- G2 or G3 squamous cell carcinoma in 37 patients (41.1\%),

- G2 or G3 partly keratinizing squamous cell carcinoma in 35 patients (38.9\%)

- G2 or G3 non-keratinizing squamous cell carcinoma in 14 patients (15.6\%),

- Partim fusocellulare squamous cell carcinoma in 1 patient (1.1\%)

All patients underwent LPE, including 20 patients with subtotal pharyngectomy and cervical oesophagectomy because of disease recurrence. Two methods were employed for digestive tract reconstruction: JA was applied in 79 patients (87.78 \%) - Group A, and IA was used in 11 patients $(12.22 \%)$ - Group B.

Venous anastomoses were performed: end-to-side between the mesenteric vein and internal jugular vein - in 89 (98.89\%) patients, and between the mesenteric vein and the external jugular vein - in $1(1.11 \%)$ patient.

Arterial anastomosis was performed between mesenteric artery by end-to-end connection with one of the branches of external carotid artery in 84 patients (93.33\%), or by joining mesenteric artery with the side of external carotid artery in 6 patients $(6.77 \%)$. The arterial vessel most frequently used for microanastomosis was the superior thyroid artery -72 patients (80.00\%) and the lingual artery -11 patients (12.22\%).

Sixty-nine patients (76.67\%) were treated with adjuvant radiotherapy at a total dose of 4000-6600 cGy. Three patients who had previously received radiotherapy were considered eligible for chemotherapy.

In both groups ( $A$ and $B$ ), the most common intraoperative complication was autograft ischaemia resulting predominantly from arterial thrombosis (Table 1).

Autograft ischaemia as a consequence of thrombosis necessitating the removal of the autograft was the most serious early postoperative complication (up to 30 days following surgery) in groups A and B, as well. Autograft necrosis was caused by either venous or arterial thrombosis. Salivary fistula developed in 3 patients on postoperative Day 10; 2 patients were cured as a result of conservative treatment and 1 patient had surgery (Table 2).

No statistically significant differences were observed between group $A$ and group $B$ in terms of the number of intraoperative and postoperative complications, both early and late.

Table 2. Numbers of early complications in both groups

$\begin{array}{lcc}\text { Early complications } & \text { Group A } & \text { Group B } \\ \text { Autograft necrosis } & 18 & 3 \\ \text { Salivary fistula } & 3 & - \\ \text { Wound infection } & 2 & 1 \\ \text { Multiorgan failure } & 1 & - \\ \text { Circulatory failure } & 1 & - \\ \text { Cerebral circulation disorders } & 1 & -\end{array}$


Table 3. Comparative analysis of discrete variables in groups $A$ and $B$

\begin{tabular}{|c|c|c|c|c|c|}
\hline Small vs. large intestine & $\begin{array}{r}\text { Multi-way and two } \\
\text { tabl }\end{array}$ & ay contingency & Two-way & contingency tab & les $(2 \times 2)$ \\
\hline $\begin{array}{l}\text { Analysed variable (verifying if there are significant } \\
\text { differences between groups of small vs. large intestine } \\
\text { for this variable) }\end{array}$ & $\begin{array}{c}\chi^{2} \text { Pearson's test } \\
(p \text {-value })\end{array}$ & $\begin{array}{c}\chi^{2} \text { NW test } \\
(p-\text { value })\end{array}$ & $\chi^{2}$ yates test & $\begin{array}{l}\text { One-sided } \\
\text { Fisher's exact } \\
\text { test }\end{array}$ & $\begin{array}{l}\text { Two-tailed } \\
\text { Fisher's exact } \\
\text { test }\end{array}$ \\
\hline Intraoperative complications $T=1, N=2$ & $p=0.97016$ & $p=0.97023$ & $p=0.70138$ & $p=0.62326$ & $p=01.0000$ \\
\hline Early complications up to 30 days post-surgery $T=1, N=2$ & $p=0.68795$ & $p=0.69147$ & $p=0.95688$ & $p=0.46488$ & $p=0.73377$ \\
\hline Early death immediately post-surgery $T=1, N=2$ & $p=0.44519$ & $p=0.30129$ & $p=0.98616$ & $p=0.58802$ & $p=01.0000$ \\
\hline Voice $T=1, N=2$ & $p=0.02027$ & $p=0.03350$ & - & - & - \\
\hline Swallowing I good, II dysphagia, III aphagia & $p=0.55298$ & $p=0.43698$ & - & - & - \\
\hline Gastrostomy final $T=1, N=2$ & $p=0.73504$ & $p=0.72588$ & $p=0.87853$ & $p=0.59812$ & $p=1.0000$ \\
\hline
\end{tabular}

Swallowing disorders requiring gastrostomy were the most serious late complications (more than 30 days after surgery), observed in 6 patients. Other complications included salivary fistula at the borderline of autograft and the pharynx (2 months after surgery) requiring surgical intervention, and mechanical occlusion of the small intestine requiring urgent surgical intervention.

Swallowing function was assessed 3 months after surgery in 57 patients from Group A and in 6 patients from Group B. Radiologic follow-up scans of the reconstructed

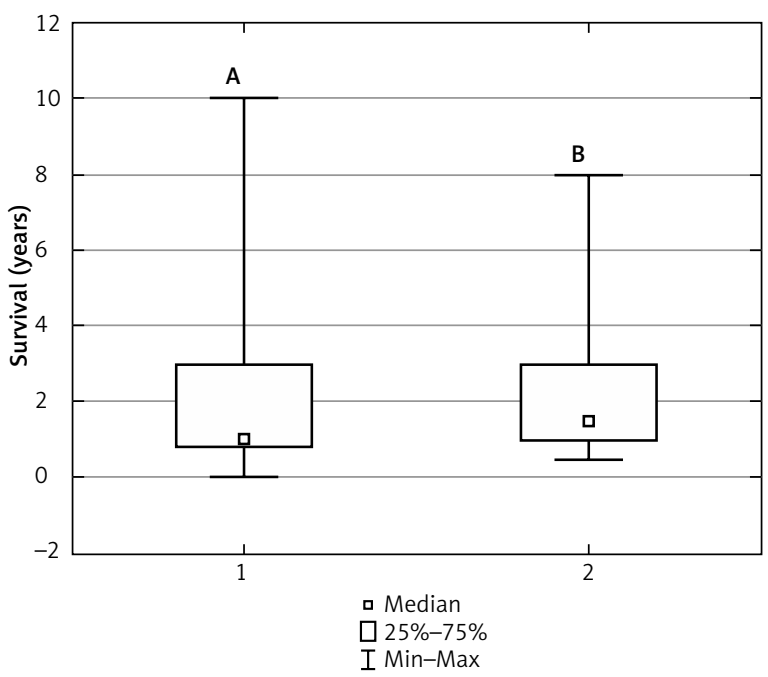

Fig. 1. Comparison of survival in Groups A and B following reconstruction surgery

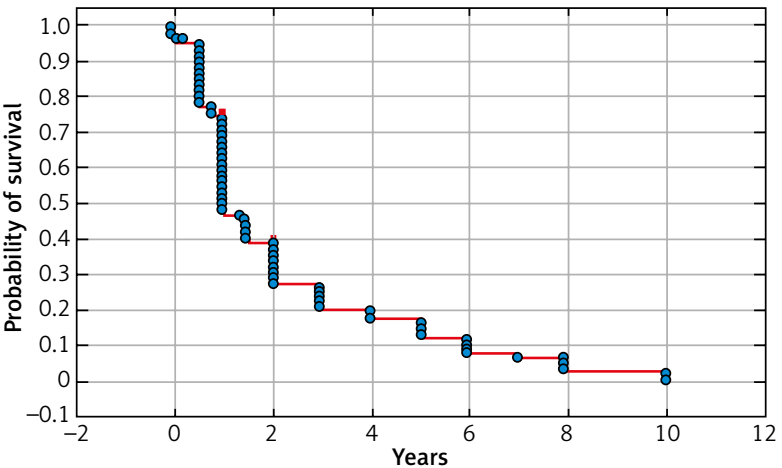

Fig. 2. Survival analysis of Group A patients after reconstruction surgery digestive tract using diluted barium sulphate showed normal autograft function in all patients. However, not all patients were able to swallow: in Group A, 33 patients could swallow normally - swallowing ability grade 1, 19 patients had dysphagia - grade 2 , and 5 patients required gastrostomy because of grade 3 swallowing dysfunction. In Group B, 1 patient was classified to grade 3 , another 1 - to grade 2 , and 4 others - to grade 1.

The voice assessment performed 3 months after surgery revealed that 50 patients from Group A produced oropharyngeal pseudo-whisper. This form of speech was understandable in approx. 5-15\%, which made communication possible only with the people being very close to the speakers. None of the patients who underwent reconstruction surgery with JA produced substitute speech at that time. Ten patients from this group received voice prostheses that enabled voice production (currently, this is standard of care). In Group B, 5 patients were able to produce speech in post-surgery week 4.

Comparative statistical analysis of discrete variables in both groups with respect to intraoperative complications, early complications, early deaths, and post-surgery swallowing as well as substitute speech revealed statistically significant differences between Group A and Group B only for oesophageal speech production. No statistically significant differences were found for other discrete variables (Table 3).

The mean survival time for patients from both groups was 2.21 years after reconstruction surgery. The most com-

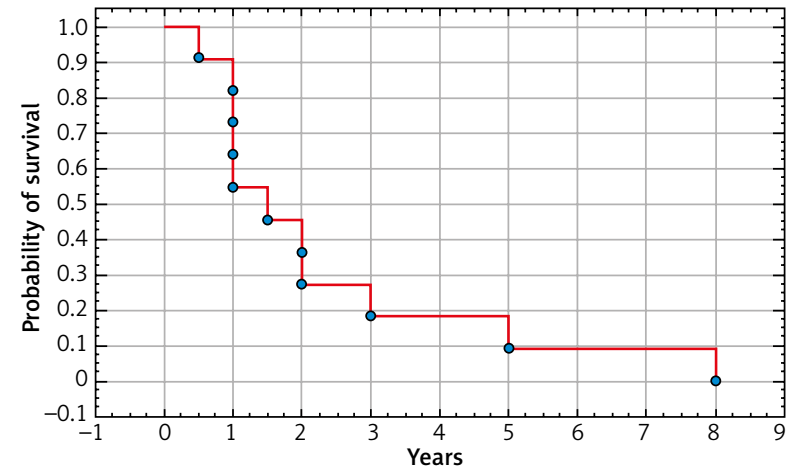

Fig. 3. Survival analysis of Group B patients after reconstruction surgery 
mon death cause was disease progression or circulatory failure.

No statistically significant differences were observed in the survival of patients between Group A and Group B (Fig. 1).

Kaplan-Meier analysis of survival probability after 6 months, 1 year, and in the following years did not show statistically significant differences (Fig. 2, 3). Cumulative survival rates 1 year and 2 years after surgery were $46.84 \%, 27.32 \%$ and $54.55 \%$, $27.27 \%$ in Group A, respectively.

\section{Discussion}

Until 1990, the standard of care in advanced hypopharyngeal cancer was surgery followed by radiotherapy. In recent years, organ-preservation therapy - radical radiochemotherapy - has been more common, with salvage surgery as the ultimate treatment $[5,6,9]$. There are different methods used for digestive tract reconstruction, and their choice depends on the facilities available at the treatment site and staff experience. These methods include jejunal free flap, tubed radical forearm free flap, and tubed anterolateral thigh free flap (ALT) [10-15]. However, no prospective randomized study has been published to indicate unequivocal superiority of one of these treatment methods over the other. Likewise, there is no consensus on the primary treatment to be used in this group of patients.

Epidemiology studies confirm that $70-80 \%$ of patients present with disease stage III or IV, and the 5-year survival rate is only $15-45 \%[1,2]$.

The most important factor affecting the prognosis in hypopharyngeal and laryngeal cancer is local disease advancement and lymph node involvement. In Poland, since the 1960s most of the cases have been those with locally advanced disease (T3 + T4) with uni- (60-80\% of patients) or bilateral (10\% of patients) metastases in cervical lymph nodes $[16,17,26]$. In the material presented in our paper, $48.89 \%$ of patients had histopathology-confirmed metastases in cervical lymph nodes, including $8 \%$ of patients with bilateral metastases. An epidemiological analysis of 19 treatment centres conducted by Bien demonstrated that metastases in regional lymph nodes were found in $46.7 \%$ of patients [16].

Our analysis focused on digestive tract reconstruction using free, vascularized jejunal and IA for which Bauhin's valve competence is crucial, because it enables speech production once a finger is placed over the tracheostomy tube.

The analysis did not reveal any statistically significant differences in the number of intraoperative and postoperative complications, both early and late. Likewise, no between-group differences were observed in post-surgery swallowing function or survival time. The only statistically significant difference regarded oesophageal speech production. In the group with reconstruction using jejunal autograft, none of the patients produced oesophageal speech, while among those who had digestive tract reconstruction using IA, 5 patients produced an oesophageal voice.

The most common and the most serious intraoperative complication observed in both groups was autograft ischaemia. According to Hsieh and many other authors [8, 11,
$18,20]$, reconstruction failure rates resulting in flap necrosis range between $0 \%$ and $17 \%$. These results usually improve as experience is gained in performing this technically challenging procedure $[4,15]$. Other complications included salivary fistula in 2 patients and postoperative wound infection. Disa et al. [21] reported that the local wound infection rate was $1 \%$; these findings were confirmed in our analysis. The rate of fistula development is reported to range between 16\% and 38\% [20-22]. The most common late complications in patients with reconstruction surgery were swallowing disorders [20, 22, 23]. According to the reports published by various authors, $60-88 \%$ of patients undergoing reconstruction surgery are able to re-introduce a normal oral diet $[20,23,24]$. It is believed that JA is superior to fasciocutaneous flaps or myocutaneous flaps, in terms of physiology [23]. The tissues devoid of peristaltic function such as skin or muscle grafts used in the reconstruction of digestive tract may cause swallowing disorders [20, 23].

One of the few but very troublesome disadvantages of reconstructing a hypopharyngeal defect with JA is the poor ability to produce substitute speech $[25,26]$. Voice rehabilitation following LPE is always very difficult because this procedure completely changes the physiological conditions for voice production. Currently, tracheoesophageal voice prostheses are the gold standard making it possible to produce satisfactory fistula speech [26]. This has been confirmed by Sharp's and Hanson's works reporting that the percentage of patients who developed socially acceptable and understandable speech was $78.9 \%$ and $69.6 \%$, respectively $[27,28]$.

Ileocolic autograft is a reconstruction method that offers the opportunity for swift substitute voice development [28]. Karri et al. reported that $76 \%$ of their patients were able to speak, but only $30 \%$ of them spoke perfectly in terms of comprehensibility [29]. Based on the analysis of 205 patients who underwent reconstruction surgery using ileocolic segment, Hsiao reported that as many as 64\% of subjects developed good voice, which supports the high efficiency of this reconstruction method [30].

\section{Conclusions}

Our study confirms that although burdened with high risk of complications, JA or IA used for digestive tract reconstruction in patients after laryngopharyngoesophagectomy offer the chance of restoring normal oral diet shortly after surgery. Ileocolic autograft is superior to JA in terms of rapid production of substitute speech.

\section{The authors declare no conflict of interest.}

\section{References}

1. Hall SF, Groomme PA, Irish J, et al. The natural history of patients with squamous cell carcinoma of the hypopharynx. Laryngoscope 2008; 118: 1362-1371.

2. Cooper JS, Porter K, Mallin K, et al. National cancer database report on cancer of the head and neck: 10-year update. Head Neck 2009; 31: 748-758. 
3. Pingree TF, Davis RK, Reichman O, Derrick L. Treatment of hypopharyngeal carcinoma: a 10-year review of 1,362 cases. Laryngoscope 1987; 97: 901-904.

4. Eckel HE, Staar S, Volling P, et al. Surgical treatment for hypophar ynx carcinoma: feasibility, mortality, and results. Otolaryngol Head Neck Surg 2001; 124: 561-569.

5. Gatta G, Botta L, Sanchez MJ, et al. Prognoses and improvement for head and neck cancers diagnosed in Europe in early 2000s: The EUROCARE-5 population-based study. Eur J Cancer 2015; 51: 2130-2143.

6. Gupta T, Chopra S, Agarwal JP, et al. Squamous cell carcinoma of the hypopharynx: single-institution outcome analysis of a large cohort of patients treated with primary non-surgical approaches. Acta Oncol 2009; 48: 541-548.

7. Pracy P, Loughran S, Goog J, et al. Hypopharyngeal cancer: United Kingdom National Multidisciplinary Guidelines. J Laryngol Otol 2016; 130: S104-S110.

8. Nazarewski S. Wolne autoprzeszczepy jelitowe w rekonstrukcji drogi pokarmowej $u$ chorych po wycięciu gardła dolnego, części szyjnej przełyku oraz krtani. Akademia Medyczna, Warszawa 2004.

9. Lefebvre JL, Andry G, Chevalier D, et al. Laryngeal preservation with induction chemotherapy for hypopharyngeal squamous cell carcinoma: 10-year results of EORTC trial 24891. Ann Oncol 2012; 23: 2708-2714.

10. Denewer A, Khater A, Hafez M, et al. Pharyngoesophageal reconstruction after resection of hypopharyngeal carcinoma: a new algorithm after analysis of 142 cases. World J Surg Oncol 2014; 12: 182

11. Elfeky AE, Nasr WF, Khazbak A, et al. Hypopharyngeal reconstruction: a comparison of three alternatives. Eur Arch Otorhinolaryngol 2015; 272: 3045-3050

12. Surkin MI, Lawson W, Biller HF. Analysis of the methods of pharyngoesophageal reconstruction. Head Neck Surg 1984; 6: 953-970.

13. Piazza C, Taglietti V, Nicolai P. Reconstructive options after total laryngectomy with subtotal or circumferential hypopharyngectomy and cervical esophagectomy. Curr Opin Otolaryngol Head Neck Surg 2012; 20: 77-88.

14. Ong GB, LeeTC. Pharyngogastric anastomosis after oesophagopharyngectomy for carcinoma of the hypopharynx and cervica oesophagus. Br J Surg 1960; 48: 193-200.

15. Perez-Smith D, Wagels M, Theile DR. Jejunal free flap reconstruction of the pharyngolaryngectomy defect: 368 consecutive cases. J Plast Reconstr Aesthet Surg 2013; 66: 9-15.

16. Bień S, Kamiński B, Żyłka S, et al. Ewolucja obrazu epidemiologicznego i klinicznego raka krtani i krtaniowej części gardła w Polsce w latach 1991-2001. Otol Pol 2005; 59: 169-181.

17. Wojciechowska U, Didkowska J, Zatoński W: Nowotwory złośliwe w Polsce w 2013 roku. Centrum Onkologii Instytut, Warszawa 2015

18. Chan YW, Ng RW, Liu LH, et al. Reconstruction of circumferential pharyngeal defects after tumour resection: reference or prefer ence. J Plast Reconstr Aesthet Surg 2011; 64: 1022-1028.

19. Chen HC, Rampazzo A, Gharb BB, et al. Motility differences in free colon and free jejunum flaps for reconstruction of the cervical esophagus. Plast Reconstr Surg 2008; 122: 1410-1416.

20. Hsieh MH, Yang YT, Tsai YJ, et al. Comparison of the outcomes of free jejunal flap reconstructions of pharyngoesophageal defects in hypopharyngeal cancer and corrosive injury patients. Microsurgery 2017; 37: 552-557.

21. Disa JJ, Pusic AL, Hidalgo DA, et al. Microvascular reconstruction of the hypopharynx: defect classification, treatment algorithm, and functional outcome based on 165 consecutive cases. Plast Reconstr Surg 2003; 111: 652-660.

22. Scherl C, Mantsopoulos K, Semrau S, et al. Management of advanced hypopharyngeal and laryngeal cancer with and without cartilage invasion. Auris Nasus Larynx 2017; 44: 333-339.

23. Takes RP, Strojan P, Silver CE, et al. Current trends in initial management of hypopharyngeal cancer: the declining use of open surgery. Head Neck 2012; 34: 270-281.
24. Chevalier D, Triboulet JP, et al. Free jejunal graft reconstruction after total pharyngolaryngeal resection for hypopharyngeal cancer. Clin Otolaryngol Allied Sci 1997; 22: 41-43.

25. Benazzo M, Bertino G, Lanza L, et al. Voice restoration after circumferential pharyngolaryngectomy with free jejunum repair. Eur Arch Otorhinolaryngol 2001; 258: 173-176.

26. Perrone F, Gharb BB, Rampazzo A, et al. Evaluation and management of complications or functional problems at the recipient site after esophageal and voice reconstruction with free ileocolon flap. Surgery 2013; 153: 373-382 e2.

27. Sharp DA, Theile DR, Cook R, et al. Long-term functional speech and swallowing outcomes following pharyngolaryngectomy with free jejunal flap reconstruction. Ann Plast Surg 2010; 64: 743-746.

28. Hanson RP, Chow TK, Feehan E, et al. Analysis of functional results and quality of life following free jejunal flaps for reconstruction after upper aerodigestive neoplastic resection: the St James's experience. J Plast Reconstr Aesthet Surg 2007; 60: 577-582.

29. Karri V, Yang MC, Chung KP, et al. Total pharyngolaryngectomy and voice reconstruction with ileocolon free flap: functional outcome and quality of life. J Plast Reconstr Aesthet Surg 2011; 64: 911-920. 30. Hsiao HT, Leu YS, Chang YC, at al. Voice and swallowing after laryngopharyngectomy and free ileocolic flap reconstruction for hypopharyngeal cancer. Ann Plast Surg 2009; 62: 390-394.

\section{Address for correspondence}

\section{Ewa Osuch-Wójcikiewicz}

Department of Otorhinolaryngology

Head and Neck Surgery

Medical University in Warsaw

1a Banacha St.

02-097 Warsaw, Poland

e-mail: ewaosuch@poczta.onet.pl, eosuch@wum.edu.pl

Submitted: 30.11 .2020

Accepted: 3.03 .2021 